\title{
Importance of Apolipoprotein A-I in Multiple Sclerosis
}

\author{
Lidia A. Gardner ${ }^{1,2 *}$ and Michael C. Levin ${ }^{1,2,3}$ \\ ${ }^{1}$ Research Service, VA Medical Center, Memphis, TN, USA, ${ }^{2}$ Department of Neurology, University of Tennessee Health \\ Science Center, Memphis, TN, USA, ${ }^{3}$ Neuroscience Institute, University of Tennessee Health Science Center, \\ Memphis, TN, USA
}

\section{OPEN ACCESS}

Edited by: Norman E. Miller, University of Oxford, UK

Reviewed by:

Partha Krishnamurthy, University of Kansas Medical Center, USA

Carmen Gil, Centro de Investigaciones Biologicas,

Spain

*Correspondence: Lidia A. Gardner lgardne5@gmail.com

Specialty section: This article was submitted to Experimental Pharmacology and Drug Discovery, a section of the journal Frontiers in Pharmacology

Received: 07 September 2015 Accepted: 04 November 2015 Published: 20 November 2015

Citation:

Gardner LA and Levin MC (2015) Importance of Apolipoprotein

A-I in Multiple Sclerosis.

Front. Pharmacol. 6:278. doi: 10.3389/fphar.2015.00278
Jean-Martin Charcot has first described multiple sclerosis (MS) as a disease of the central nervous system (CNS) over a century ago. MS remains incurable today, and treatment options are limited to disease modifying drugs. Over the years, significant advances in understanding disease pathology have been made in autoimmune and neurodegenerative components. Despite the fact that brain is the most lipid rich organ in human body, the importance of lipid metabolism has not been extensively studied in this disorder. In MS, the CNS is under attack by a person's own immune system. Autoantigens and autoantibodies are known to cause devastation of myelin through up regulation of T-cells and cytokines, which penetrate through the blood-brain barrier to cause inflammation and myelin destruction. The anti-inflammatory role of highdensity lipoproteins (HDLs) has been implicated in a plethora of biological processes: vasodilation, immunity to infection, oxidation, inflammation, and apoptosis. However, it is not known what role HDL plays in neurological function and myelin repair in MS. Understanding of lipid metabolism in the CNS and in the periphery might unveil new therapeutic targets and explain the partial success of some existing MS therapies.

Keywords: HDL, ApoA-I, multiple sclerosis, CNS, ATP- binding cassette transporter A1, sphingosine 1 phosphate, FTY720 (fingolimod, Gilenya)

\section{CHOLESTEROL SYNTHESIS}

Lipoproteins contain triacylglycerols, cholesterol esters, cholesterol and phospholipids. They exist in two main forms: high- and low-density lipoproteins (LDLs). These hydrophobic aggregates covalently bind to apoproteins to form apolipoproteins. As major components of lipoproteins, apoproteins determine their structure, metabolism, receptor interaction and function. The primary apolipoprotein of high-density lipoprotein (HDL) is apolipoprotein A-I or ApoA-I, while major component of LDL is ApoB.

In mammals peripheral cholesterol is produced in the liver and the small intestine. Cholesterol biosynthesis involves as many as 30 enzymatic steps. Cells produce cholesterol from acetylCoA, which is reduced to mevalonate by 3-hydroxy-3-methylglutaryl-CoA reductase (HMGCR). Through a series of reactions, mevalonate is converted to squalene and lanosterol and then to 7dehydrocholesterol, 7-dehydrocholesterol reductase produces a cholesterol molecule. Cholesterol can be hydroxylated to 24-, 25-, and 27-hydroxycholesterol (27-OHC) by the CYP46 hydroxylase. Healthy cholesterol homeostasis is necessary for membrane formation, function of steroid hormones, vitamin $\mathrm{D}$, and adequate brain function. Cholesterol is also an important myelin component and a precursor of oxysterols, steroid hormones and bile acids. 


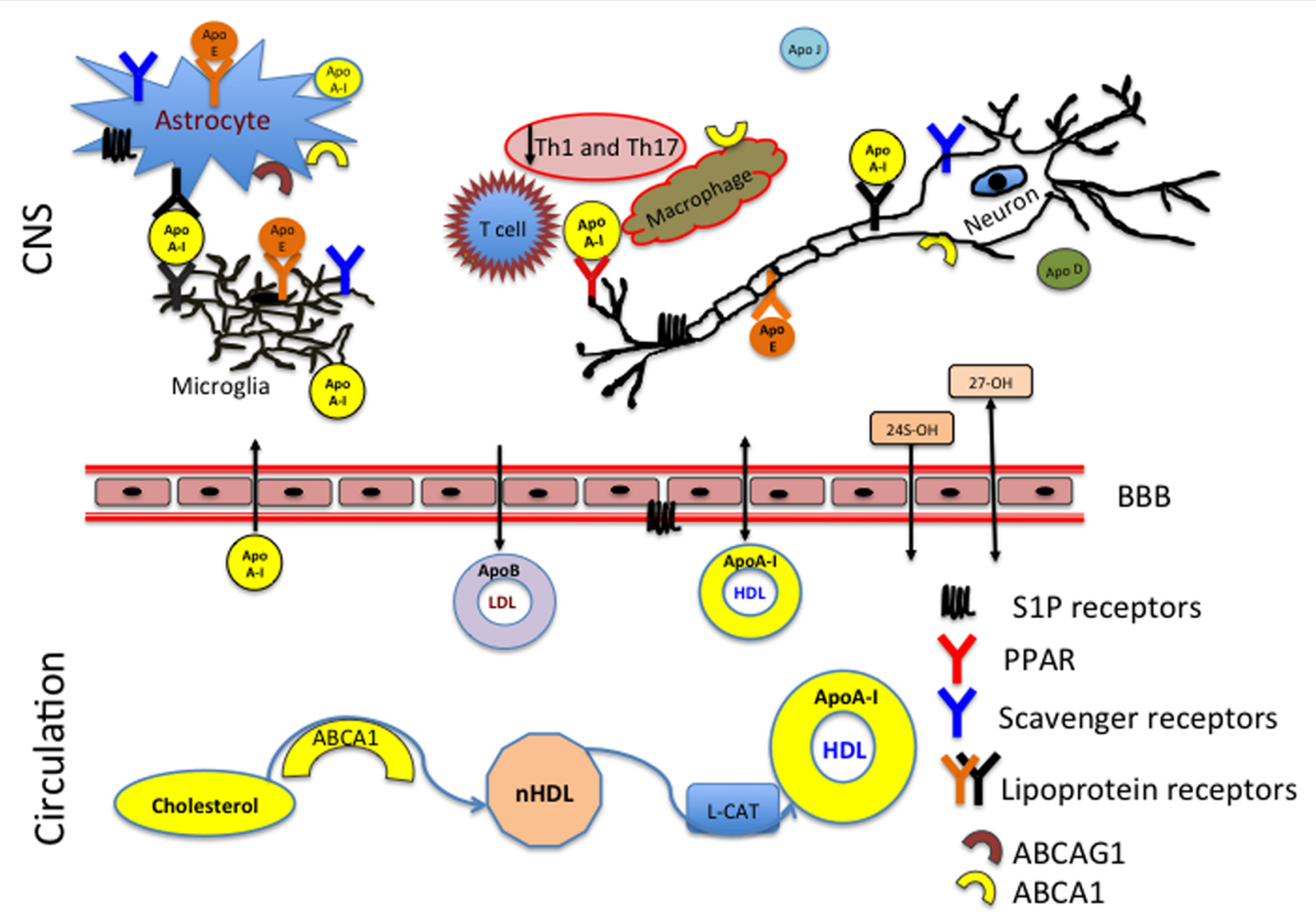

FIGURE 1 | ApoA-I reduces inflammation in the CNS by preventing contact between the T cells and macrophages. HDL produced in the periphery has access to the CNS whereas LDL has no ability to enter the CNS from the circulation. The membrane associated ATP-binding cassette subfamily A member 1 (ABCA1) and ABCA G1 act as the primary sterol transporters for ApoA-l/HDL. HDL associated ApoA-l is then recognized by the lipoprotein receptors (LDL, SR-BI) in the CNS. Brain cholesterol homeostasis is supported by the reverse cholesterol transport and efflux of $24(24 \mathrm{~S}-\mathrm{OH})$ and $27(27-\mathrm{OH})$ hydroxysterols through the blood-brain barrier (BBB).

Excess cholesterol is removed from tissues through a process known as reverse cholesterol transport, during which cholesterol from the periphery is returned to the liver for biliary excretion. In plasma a membrane associated ATP-binding cassette transporter A1 (ABCA1) promotes efflux of free cholesterol (FC), sphingomyelin (SM), glycerophosphocholine (PC) to ApoA-I to form nascent HDL (nHDL; Sorci-Thomas et al., 2012). This process regulates HDL levels in the periphery (Figure 1). ABCA1 also functions to contain cholesterol within lipid rafts (Vedhachalam et al., 2007; Fessler and Parks, 2011). Lipids rafts were first described as membrane microdomains consisting of both protein and lipid components (de Chaves et al., 1997).

In the central nervous system (CNS), lipid rafts are present in neurons and glia and are believed to play a role in neuronal signaling, cell adhesion and axonal guidance (de Chaves et al., 1997; Tsui-Pierchala et al., 2002). Cholesterol being at the core of a lipid raft formations, plays an important structural and functional role. In addition to cholesterol, lipid rafts contain sphingolipid enriched microdomains that regulate membrane trafficking, cell migration, and variety of signaling pathways (Simons and Ikonen, 1997).
Lipoproteins, apoproteins, and apolipoproteins can be found in circulation in free or nascent form, but lipid rafts are always associated with cellular membranes. It is unclear whether apolipoproteins require any scaffolding support of the raft for their function, but it is certain that lipid rafts need the presence of cholesterol, lipids, and proteins.

The exact role of lipid rafts in the pathogenesis of multiple sclerosis (MS) and other diseases remains to be discovered. Different brain regions have diverse cholesterol requirements and enrichment in membrane rafts (Ko et al., 2005). In addition, lipid rafts play an important role in receptor signaling. Because the brain is the most lipid rich organ in the human body it has large amounts of lipid rafts associated with brain cell membranes, lymphatic vessels and CNS vasculature (Bjorkhem and Meaney, 2004; Orth and Bellosta, 2012; Vance, 2012; Louveau et al., 2015).

\section{HDL AFFECTS SPHINGOSINE RECEPTORS}

Sphingolipids are metabolized to generate ceramide and sphingosine. Sphingosine can be phosphorylated by sphingosine kinase to generate S1P (sphingosine 1-phosphate; Scanu and 
Edelstein, 2008). S1P is enriched in platelets, erythrocytes, vascular endothelial cells, and plasma (Scanu and Edelstein, 2008). HDL carries biologically active S1P as part of its composition (Al-Jarallah et al., 2014). S1P receptors play a key role in lymphocyte function, which might explain the efficacy of FTY720 (fingolimod, brand name Gilenya) an oral treatment for MS. Clinical trials of FTY720 showed reduction in relapses, brain magnetic resonance imaging (MRI) lesion activity, disability progression, and brain volume loss (Kappos et al., 2006, 2010; Cohen et al., 2010). The exact mechanism of action of FTY720 in MS is not known (Cohen and Chun, 2011). However, it is presumed that FTY720 reduces infiltration of inflammatory cells through blood-brain barrier (BBB) by inhibition of lymphocyte egress from the lymph nodes. FTY720 is a synthetic sphingosine analog, which activates the S1P receptor (Mansoor and Melendez, 2008). FTY720 reduces the count of circulating lymphocytes by inducing S1P receptor internalization and degradation, which may contribute to its success in MS treatment (Pacheco et al., 2003; Spiegel and Milstien, 2003). FTY720 also affects production of IL-17 expressing T-cells and trafficking of B-cells, which has been shown to contribute to the pathogenesis of MS (Brinkmann, 2009; Mehling et al., 2010).

In addition to reducing lymphocyte quantity, S1P activates many signaling pathways including PI3K-Akt, PKC, p38MAPK, ERK1/2, and AKT-mTOR (Liu et al., 2010; Al-Jarallah et al., 2014). FTY720 reduced cholesterol toxicity in primary human macrophages, increased levels of ABCA1 and consequently efflux of endosomal cholesterol to ApoA-I, and stimulated $27-\mathrm{OH}$ production (Blom et al., 2010). This and other studies highlighted the pleiotropic effect of FTY720. FTY720 might have direct CNS effects since it lowered disability progression and brain volume loss in MS patients (Cohen and Chun, 2011). S1P is produced in the CNS by astrocytes and neurons. The $\mathrm{S}_{1} \mathrm{P}_{1}$ and $\mathrm{S} \mathrm{P}_{3}$ receptors are activated in active and chronic MS lesions (Van Doorn et al., 2010). Endothelial cells and astrocytes of the BBB also express S1P receptors and FTY720 has been shown to reduce the effects of the cell death induced by inflammatory cytokines (Prager et al., 2015; Spampinato et al., 2015). Moreover, the neuroprotective effect of FTY720 could be explained by the fact that S1P receptors involved in HDL-induced inhibition of adhesion molecules [intercellular adhesion molecule 1 (ICAM1) and vascular cell adhesion molecule 1 (VCAM-1)] expression under inflammatory conditions (Kimura et al., 2006).

\section{REGULATION OF LIPID METABOLISM IN THE CNS}

The CNS has it's own cholesterol production and transport system. For the most part, it operates independently from peripheral cholesterol synthesis (Bjorkhem and Meaney, 2004; Orth and Bellosta, 2012; Vance, 2012). However, in diseases such as MS, the BBB is often compromised and apolipoproteins can easily carry cholesterol synthetized in the periphery to the CNS; thus altering cholesterol homeostasis behind the barrier. Brain cholesterol is synthetized by astrocytes, oligodendrocytes and neurons. Step-by-step CNS cholesterol biosynthesis is not entirely understood. However, studies have shown that enzymes responsible for cholesterol formation such as HMGCR and 7dehydrocholesterol reductase have high expression in cortical cholinergic and hippocampal neurons (Ong et al., 2010).

The majority of the CNS cholesterol is present in unesterified form within myelin sheaths, plasma membranes of glial and neuronal cell (Bjorkhem and Meaney, 2004).

It is worthy to note that myelin lipid-protein composition is different from other cell membranes. Myelin's dry weight is about $70 \%$ lipid and $30 \%$ protein, while other membranes have $30 \%$ lipid and $70 \%$ protein in their dry weight (Bjorkhem and Meaney, 2004). In MS, neurological symptoms are the result of loss of myelin sheaths around axons, which prevents transmission of nerve impulses. More than $95 \%$ of brain cholesterol is synthetized de novo from acetate (Dietschy and Turley, 2001). The HMGCR mediates the rate-limiting step of cholesterol biosynthesis. Excess cholesterol is converted into cholesterol ester by acyl CoA: cholesterol acyltransferase or to 24S-hydroxysterol $(24-\mathrm{OH})$ by CYP46 expressed in neurons (Lund et al., 1999). The efflux of brain-produced cholesterol can be quantified based on the $24 \mathrm{~S}$ $\mathrm{OH}$ present in the mammalian system (Locatelli et al., 2002; Mailman et al., 2011).

In brain, oxidation of the steroid chain at position 24 is a primary mechanism of elimination of cholesterol excess (Figure 1). Outside of the brain, the oxidation occurs at position 27 by CYP27A1, expressed primarily on macrophages (Heverin et al., 2005). MS patients have decreased serum levels of both sterols: $24 \mathrm{~S}-\mathrm{OH}$ and $27-\mathrm{OH}$ (van de Kraats et al., 2014). This suggests that disturbances in cholesterol homeostasis might relate to the neurodegeneration and disease pathology. 27-OHC produced in the periphery can penetrate through the BBB and be taken up by scavenger class B type I (SR-BI) receptors (Figure 1). The levels of 27-OHC are different in cerebrospinal fluid (CSF) of healthy adults and patients with compromised BBB (Leoni et al., 2003). SR-BI was identified as an HDL receptor in 1996 (Acton et al., 1996). SR-BI is predominantly localized to astrocytes, microglia, and macrophages (El Khoury et al., 2003; Song et al., 2015). The two most important types of receptors involved in cholesterol homeostasis are the LDL and HDL receptors. LDL receptors are highly expressed in the brain white matter and in astrocytes and their function has been extensively studied in health and disease (Kim et al., 2009; Castellano et al., 2012). The structure and property of HDL receptors continues to evolve in scientific literature (Acton et al., 1996; Webb et al., 1998; AlJarallah et al., 2014; Kartz et al., 2014; Chadwick et al., 2015; Song et al., 2015).

Other receptors such as peroxisome proliferator-activated receptors (PPAR) are expressed in the CNS and are involved in regulation of lipid metabolism, control of inflammation, and cholesterol transport (Bocher et al., 2002; Hulshagen et al., 2008; Chrast et al., 2011; Varga et al., 2011). PPARs form heterodimers with retinoid $\mathrm{X}$ receptor (RXR) and regulate inflammatory responses, myelin synthesis, neuronal cell proliferation and differentiation, energy and lipid homeostasis, and reactive oxygen species. Among the three subtypes of PPARs, PPAR $\alpha$, and PPAR $\gamma$ are present on macrophages, $T$ cells, foam cells, and smooth muscle cells (Harris and Phipps, 2001; Yang et al., 2008). Activation of PPAR $\alpha$ up regulates HDL production and 
ApoA-I expression (Mikael et al., 2006). PPAR $\beta / \delta$ is involved in control of brain lipid metabolism and epidermal cell proliferation (Heneka et al., 2000; Schmidt et al., 2004). The use of PPAR agonists in MS and its mouse model known as experimental autoimmune encephalomyelitis (EAE) has been explored with some positive results. For example, PPAR $\gamma$ ligands reduced leukocyte infiltration into the brain parenchyma and decreased both inflammation and axonal degeneration in EAE (Niino et al., 2001; Feinstein et al., 2002; Smith et al., 2004; Polak et al., 2005). PPAR antagonist GW347845 suppressed T-cell proliferation and reduced secretion of tumor necrosis factor alpha (TNF $\alpha)$ and interferon gamma (INF $\gamma$ ) in peripheral mononuclear cells (PBMCs) from MS patients (Schmidt et al., 2004). However, these effects were accompanied by reduced cell viability and induced apoptosis of inactivated lymphocytes. These studies suggest that activation of PPARs, and specifically PPAR $\alpha$ can increase synthesis of HDL and ApoA-I to aid cholesterol biosynthesis and reverse transport.

\section{MAJOR PLAYERS OF REVERSE CHOLESTEROL TRANSPORT}

Apolipoproteins play a major role in cholesterol recycling process-reverse cholesterol transport within the CNS and in the periphery. Production of cholesterol in the brain peaks during myelogenesis, when glial cells and neurons produce it. Mature neurons seems to loose cholesterol-producing capacity and rely instead on cholesterol delivering lipoproteins to maintain ongoing needs. Several studies indicate a role for apolipoproteins in cholesterol transfer and lipid metabolism in the CNS (Lewis et al., 2010; Takechi et al., 2010; Song et al., 2012). Among six major classes of Apolipoproteins (A, B, C, D, E, and H) only apolipoprotein $\mathrm{E}$ (ApoE) has been studied extensively in neurobiology. ApoE is produced by astrocytes and glial cells, and is overexpressed in human brain. ApoA-I is prevalent in the CSF but not in the brain. Abundant evidence implicates ApoE and specifically its E4 allele involvement in Alzheimer's disease (Corder et al., 1993; Puglielli et al., 2003; Canevari and Clark, 2007). ApoA-I levels were decreased in serum, plasma and CSF of patients with Alzheimer's disease compared to healthy controls (Kawano et al., 1995; Liu et al., 2006; Roher et al., 2009). Levels of ApoA-I decline with age, however levels below $110 \mathrm{mg} / \mathrm{dL}$ might indicate predisposition to neurodegenerative diseases. Several studies have shown that overexpression of ApoA-I prevented the development of age-related learning and memory deficits in transgenic mice (Kawano et al., 1995; Liu et al., 2006; Roher et al., 2009; Lewis et al., 2010). These studies indicate the importance of ApoA-I in the neurodegenerative diseases of the CNS.

ApoA-I is not synthetized in the brain, however it has the ability to penetrate the BBB and solicit anti-inflammatory and neuroprotective effects in the brain (Figure 1).

In addition to participating in the CNS reverse cholesterol transport, ApoA-I blocks macrophage interactions with T-cells. This results in reduction of the Th1 and Th17 associated cytokines (Figure 1). Both ABCA1 and ABCAG1 are highly expressed on astrocytes, microglia, neurons, macrophages and $\mathrm{T}$ cells, which indicates that there is an active cholesterol turnover between multiple components. The brain is a highly compartmentalized organ with different regions expressing different need in cholesterol synthesis and transport.

The liver X receptor (LXR) is a transcription factor expressed in the liver, macrophages, and neurons. It is noteworthy that $24 \mathrm{~S}-\mathrm{OH}$ is a ligand for LXRs, which activates expression of ABCA1, ApoAI, and ApoE. Mice lacking LXRs had impaired cholesterol removal (Joseph et al., 2003). Murine deficiency in ABCA1 resulted in greater ApoA-I retention in the CNS compared to the periphery (Stukas et al., 2012). Moreover, LXR agonist GW3965 increased ApoA-I production in the brain independent from ABCA1. Thus indicating that ApoA-I may serve to integrate peripheral and CNS metabolism (Stukas et al., 2012). Overall, lipid abnormalities and cholesterol metabolism play important roles in neurological diseases (Dietschy and Turley, 2001; Bjorkhem and Meaney, 2004). Two additional apolipoproteins ApoJ and ApoD have been found in the CNS. Their function is poorly defined, beyond of proposed role as transporter proteins.

\section{THE ROLE OF APOA-I IN MULTIPLE SCLEROSIS}

ApoA-I is the most abundant component of HDL (Sorci-Thomas et al., 2012). HDL-associated ApoA-I may play a role in neuronal regeneration by acting as a constitutive anti-inflammatory factor (Hyka et al., 2001; Pfrieger, 2003; Jimenez et al., 2005). Several studies pointed out a possible protective role of ApoA-I in inflammation and autoimmunity (Panin et al., 2005; Vollbach et al., 2005; Koutsis et al., 2009; Wilhelm et al., 2009; Robciuc et al., 2010; Serban et al., 2010; Shiga et al., 2010). Differential ApoA-I expression was recognized in the CSF and serum of MS patients (Gandhi et al., 2010). In addition, ApoA-I may play a role in neuronal regeneration by acting as a constitutive antiinflammatory factor (Burger and Dayer, 2002; Vollbach et al., 2005). However, there are major gaps in our understanding of ApoA-I regulatory mechanisms and its involvement in MS.

ApoA-I has been described as a putative clinical biomarker for interferon beta (INF $\beta$ ) treatment (Gandhi et al., 2010). Study subjects, who had high levels of serum ApoA-I, responded better to INF $\beta$ therapy, a common immunomodulatory treatment for relapsing remitting MS patients. This was possibly due to the reduced inflammation associated with increased HDL levels. ApoA-I has been shown to play a role in the cognitive abilities of MS patients (Koutsis et al., 2009). Cognitive impairment is associated with a lack of APOA1 allele. Specifically, carriers of this allele performed significantly better on semantic verbal fluency and Stroop interference tests (Koutsis et al., 2009). This study evaluated $138 \mathrm{MS}$ patients and 43 controls and the authors concluded that there is an association of the APOA1-75G/A promoter polymorphism with cognitive performance.

We discovered that advanced MS patients have lower plasma ApoA-I levels in comparison to patents with stable relapsing remitting disease and healthy age-matched controls (Meyers et al., 2014). Patients with primary and secondary progressive MS had the lowest levels of ApoA-I. A negative correlation between the amount of this protein and disease symptom worsening in MS was also noted. In addition, mice deficient in murine ApoA-I protein 
developed more severe EAE disease compared to the wild type animals with normal ApoA-I levels (Meyers et al., 2014). Our data indicate that ApoA-I levels decline with disease progression (Gardner et al., 2013; Meyers et al., 2014). Therefore, preventing ApoA-I levels from decreasing might prove beneficial for MS patients.

Another group assessed serum lipid profiles of 492 MS patients for associations with disability and MRI outcomes (WeinstockGuttman et al., 2011). The authors reported that higher HDL was associated with lower levels of acute inflammation and worsening in the expanded disability status scale (EDSS). High EDSS was associated with higher baseline LDL and total cholesterol. A prospective population-based cohort study found an association between adverse lipid profile and high levels of MS disability and disease progression (Tettey et al., 2014). The authors shown that total cholesterol, ApoB and ApoB/ApoA-I ratio were independently associated with higher EDSS.

Given the fact that ApoA-I is expressed at high levels in spinal fluid, and perturbations in lipid metabolism negatively affect myelin, factors that control ApoA-I production and turnover should receive special consideration (Hulshagen et al., 2008; Chrast et al., 2011; Levin et al., 2014). Levels of ApoA-I could be raised with statins, however use of statin medication in MS patients delivered conflicting results (Vollmer et al., 2004; Lock, 2008; Maier et al., 2009; Markovic-Plese et al., 2009; Chataway et al., 2012).

A pilot study of $30 \mathrm{MS}$ patients demonstrated a significant decrease in the number and volume of contrast enhancing lesions with $80 \mathrm{mg}$ of simvastatin treatment (Vollmer et al., 2004). A large safety and efficacy of natalizumab in combination with INF $\beta$-1A in patents with relapsing remitting multiple sclerosis (SENTINEL) study did not indicate any effect of statins on relapse rate, disability progression or the number of contrast enhancing lesions (Rudick et al., 2009). Simvastatin treatment combined with INF $\beta$ did not provide benefit for MS patients (Sorensen et al., 2011). A recent double blind, placebo-controlled MS-STAT clinical trial has shown that high dose simvastatin attenuates brain atrophy, the main reason of which is believed to be a decreased neuroaxonal loss (Chataway et al., 2014). This study, recruited MS patients with secondary progressive disease, who did not receive other disease modifying drugs. Reduction in total cholesterol levels correlated with reduction in brain atrophy in this trial. The authors did not directly measure ApoA-I levels in MS patients, however because of the known effects of simvastatin on cholesterol metabolism

\section{REFERENCES}

Acton, S., Rigotti, A., Landschulz, K. T., Xu, S., Hobbs, H. H., and Krieger, M. (1996). Identification of scavenger receptor SR-BI as a high density lipoprotein receptor. Science 271, 518-520. doi: 10.1126/science.271. 5248.518

Al-Jarallah, A., Chen, X., Gonzalez, L., and Trigatti, B. L. (2014). High density lipoprotein stimulated migration of macrophages depends on the scavenger receptor class B, type I, PDZK1 and Akt1 and is blocked by sphingosine 1 phosphate receptor antagonists. PLoS ONE 9:e106487. doi: 10.1371/journal.pone.0106487

Bjorkhem, I., and Meaney, S. (2004). Brain cholesterol: long secret life behind a barrier. Arterioscler. Thromb. Vasc. Biol. 24, 806-815. doi: 10.1161/01.ATV.0000120374.59826.1b
(Matthan et al., 2003), the data strongly suggest that HDL and Apo A-I levels were higher in simvastatin group, where cholesterol was reduced from 5.5 to $4.1 \mathrm{mmol} / \mathrm{L}$ and brain atrophy was reduced by 43\% (Chataway et al., 2014).

Low ApoA-I presence in progressive patients' plasma as we discovered in our study (Meyers et al., 2014) could explain success of high dose simvastatin treatment in this large placebo controlled phase 2 trial (Chataway et al., 2014). The controversial results of statin use in MS could be partially elucidated by the fact that statins increase reactive oxygen species, elevate lipid peroxidation and induce oxidative DNA damage in human peripheral blood lymphocytes (Gajski et al., 2008; Qi et al., 2013). Increased lipid peroxidation is associated with disease exacerbation periods and lesion pathogenesis in MS patients (Toshniwal and Zarling, 1992; Levin et al., 2013). Therefore different type of drugs, which stimulate ApoA-I production, might prove beneficial for progressive MS patients.

\section{CONCLUSION}

Apolipoproteins are important players in cholesterol homeostasis. ApoA-I acting as a major HDL component is involved in both HDL biosynthesis and transport. In CNS diseases with compromised $\mathrm{BBB}$, healthy cholesterol turnover becomes extremely important for neuronal homeostasis and regeneration. In as much as the S1P receptor agonist fingolimod, Apo-I's function is not completely understood in MS. However, data suggests a positive neuroprotective effect of this apolipoprotein on the immune and the CNSs. Reduction in ApoA-I levels has not been shown to cause MS. However for progressive patients, maintaining normal levels of ApoA-I might result in better neuronal health. Agents designed to improve ApoA-I production should be considered for therapeutic purposes. For example, PPAR agonists are one class of medications that regulate ApoAI and subsequently HDL synthesis. Therefore, studies aimed at compounds responsible for ApoA-I expression during periods of inflammation could provide important information about the mechanisms of HDL regulation and its role in MS pathogenesis.

\section{FUNDING}

This work was funded by the pilot grant from the National Multiple Sclerosis Society (A13-04262-001) to LAG and the VA Merit Review Award (BX001996-01A1) to MCL.

Blom, T., Back, N., Mutka, A. L., Bittman, R., Li, Z., de Lera, A., et al. (2010). FTY720 stimulates 27-hydroxycholesterol production and confers atheroprotective effects in human primary macrophages. Circ. Res. 106, 720-729. doi: 10.1161/CIRCRESAHA.109.204396

Bocher, V., Pineda-Torra, I., Fruchart, J. C., and Staels, B. (2002). PPARs: transcription factors controlling lipid and lipoprotein metabolism. Ann. N. Y. Acad. Sci. 967, 7-18. doi: 10.1111/j.1749-6632.2002.tb04258.x

Brinkmann, V. (2009). FTY720 (fingolimod) in Multiple Sclerosis: therapeutic effects in the immune and the central nervous system. Br. J. Pharmacol. 158, 1173-1182. doi: 10.1111/j.1476-5381.2009.00451.x

Burger, D., and Dayer, J. M. (2002). High-density lipoprotein-associated apolipoprotein A-I: the missing link between infection and chronic inflammation? Autoimmun. Rev. 1, 111-117. doi: 10.1016/s15689972(01)00018-0 
Canevari, L., and Clark, J. B. (2007). Alzheimer's disease and cholesterol: the fat connection. Neurochem. Res. 32, 739-750. doi: 10.1007/s11064-006-9200-1

Castellano, J. M., Deane, R., Gottesdiener, A. J., Verghese, P. B., Stewart, F. R., West, T., et al. (2012). Low-density lipoprotein receptor overexpression enhances the rate of brain-to-blood $\mathrm{A} \beta$ clearance in a mouse model of $\beta$-amyloidosis. Proc. Natl. Acad. Sci. U.S.A. 109, 15502-15507. doi: 10.1073/pnas.1206446109

Chadwick, A. C., Jensen, D. R., Peterson, F. C., Volkman, B. F., and Sahoo, D. (2015). Expression, purification and reconstitution of the C-terminal transmembrane domain of scavenger receptor BI into detergent micelles for NMR analysis. Protein Expr. Purif. 107, 35-42. doi: 10.1016/j.pep.2014.11.001

Chataway, J., Alsanousi, A., Chan, D., MacManus, D., Hunter, K., Foster, J., et al. (2012). "The MS-STAT trial: high dose simvastatin demonstrates neuroprotection without immune-modulation in secondary progressive multiple sclerosis (SPMS) - a phase II trial," in Proceedings of the 28th Congress of the European Committee for Treatment and Research in Multiple Sclerosis (ECTRIMS), Lyon.

Chataway, J., Schuerer, N., Alsanousi, A., Chan, D., Macmanus, D., Hunter, K., et al. (2014). Effect of high-dose simvastatin on brain atrophy and disability in secondary progressive multiple sclerosis (MS-STAT): a randomised, placebo-controlled, phase 2 trial. Lancet 383, 2213-2221. doi: 10.1016/S01406736(13)62242-4

Chrast, R., Saher, G., Nave, K. A., and Verheijen, M. H. (2011). Lipid metabolism in myelinating glial cells: lessons from human inherited disorders and mouse models. J. Lipid Res. 52, 419-434. doi: 10.1194/jlr.R009761

Cohen, J. A., Barkhof, F., Comi, G., Hartung, H. P., Khatri, B. O., Montalban, X., et al. (2010). Oral fingolimod or intramuscular interferon for relapsing multiple sclerosis. N. Engl. J. Med. 362, 402-415. doi: 10.1056/NEJMoa09 07839

Cohen, J. A., and Chun, J. (2011). Mechanisms of fingolimod's efficacy and adverse effects in multiple sclerosis. Ann. Neurol. 69, 759-777. doi: 10.1002/ana.22426

Corder, E. H., Saunders, A. M., Strittmatter, W. J., Schmechel, D. E., Gaskell, P. C., Small, G. W., et al. (1993). Gene dose of apolipoprotein E type 4 allele and the risk of Alzheimer's disease in late onset families. Science 261, 921-923. doi: $10.1126 /$ science. 8346443

de Chaves, E. I., Rusinol, A. E., Vance, D. E., Campenot, R. B., and Vance, J. E. (1997). Role of lipoproteins in the delivery of lipids to axons during axonal regeneration. J. Biol. Chem. 272, 30766-30773. doi: 10.1074/jbc.272.49. 30766

Dietschy, J. M., and Turley, S. D. (2001). Cholesterol metabolism in the brain. Curr. Opin. Lipidol. 12, 105-112. doi: 10.1097/00041433-200104000-00003

El Khoury, J. B., Moore, K. J., Means, T. K., Leung, J., Terada, K., Toft, M., et al. (2003). CD36 mediates the innate host response to $\beta$-amyloid. J. Exp. Med. 197, 1657-1666. doi: 10.1084/jem.20021546

Feinstein, D. L., Galea, E., Gavrilyuk, V., Brosnan, C. F., Whitacre, C. C., Dumitrescu-Ozimek, L., et al. (2002). Peroxisome proliferator-activated receptor-gamma agonists prevent experimental autoimmune encephalomyelitis. Ann. Neurol. 51, 694-702. doi: 10.1002/ana.10206

Fessler, M. B., and Parks, J. S. (2011). Intracellular lipid flux and membrane microdomains as organizing principles in inflammatory cell signaling. J. Immunol. 187, 1529-1535. doi: 10.4049/jimmunol.1100253

Gajski, G., Garaj-Vrhovac, V., and Orescanin, V. (2008). Cytogenetic status and oxidative DNA-damage induced by atorvastatin in human peripheral blood lymphocytes: standard and Fpg-modified comet assay. Toxicol. Appl. Pharmacol. 231, 85-93. doi: 10.1016/j.taap.2008.03.013

Gandhi, K. S., McKay, F. C., Diefenbach, E., Crossett, B., Schibeci, S. D., Heard, R. N., et al. (2010). Novel approaches to detect serum biomarkers for clinical response to interferon- $\beta$ treatment in multiple sclerosis. PLoS ONE 5:e10484. doi: 10.1371/journal.pone.0010484

Gardner, L. A., Groover, C. J., Bradley, C. S., and Levin, M. C. (2013). “A potential role for apolipoprotein A1 in multiple sclerosis" in Neuroscience Meeting Planner Program \#404.01 Multiple Sclerosis: Molecular and Cellular Mechanisms of Demyelination and Neurodegeneration Nanosymposium. Research Service VAMC, University of Tennessee Health Science Center, Memphis, TN.

Harris, S. G., and Phipps, R. P. (2001). The nuclear receptor PPAR gamma is expressed by mouse T lymphocytes and PPAR gamma agonists induce apoptosis. Eur. J. Immunol. 31, 1098-1105.

Heneka, M. T., Klockgether, T., and Feinstein, D. L. (2000). Peroxisome proliferatoractivated receptor-gamma ligands reduce neuronal inducible nitric oxide synthase expression and cell death in vivo. J. Neurosci. 20, 6862-6867.
Heverin, M., Meaney, S., Lutjohann, D., Diczfalusy, U., Wahren, J., and Bjorkhem, I. (2005). Crossing the barrier: net flux of 27-hydroxycholesterol into the human brain. J. Lipid Res. 46, 1047-1052. doi: 10.1194/jlr.M500024-JLR200

Hulshagen, L., Krysko, O., Bottelbergs, A., Huyghe, S., Klein, R., Van Veldhoven, P. P., et al. (2008). Absence of functional peroxisomes from mouse CNS causes dysmyelination and axon degeneration. J. Neurosci. 28, 4015-4027. doi: 10.1523/JNEUROSCI.4968-07.2008

Hyka, N., Dayer, J. M., Modoux, C., Kohno, T., Edwards, C. K., RouxLombard, P. III, et al. (2001). Apolipoprotein A-I inhibits the production of interleukin- $1 \beta$ and tumor necrosis factor- $\alpha$ by blocking contact-mediated activation of monocytes by $\mathrm{T}$ lymphocytes. Blood 97, 2381-2389. doi: 10.1182/blood.V97.8.2381

Jimenez, C. R., Stam, F. J., Li, K. W., Gouwenberg, Y., Hornshaw, M. P., De Winter, F., et al. (2005). Proteomics of the injured rat sciatic nerve reveals protein expression dynamics during regeneration. Mol. Cell. Proteomics 4, 120-132. doi: 10.1074/mcp.M400076-MCP200

Joseph, S. B., Castrillo, A., Laffitte, B. A., Mangelsdorf, D. J., and Tontonoz, P. (2003). Reciprocal regulation of inflammation and lipid metabolism by liver X receptors. Nat. Med. 9, 213-219. doi: 10.1038/nm820

Kappos, L., Antel, J., Comi, G., Montalban, X., O’Connor, P., Polman, C. H., et al. (2006). Oral fingolimod (FTY720) for relapsing multiple sclerosis. N. Engl. J. Med. 355, 1124-1140. doi: 10.1056/NEJMoa052643

Kappos, L., Radue, E. W., O’Connor, P., Polman, C., Hohlfeld, R., Calabresi, P., et al. (2010). A placebo-controlled trial of oral fingolimod in relapsing multiple sclerosis. N. Engl. J. Med. 362, 387-401. doi: 10.1056/NEJMoa0909494

Kartz, G. A., Holme, R. L., Nicholson, K., and Sahoo, D. (2014). SR-BI/CD36 chimeric receptors define extracellular subdomains of SR-BI critical for cholesterol transport. Biochemistry 53, 6173-6182. doi: 10.1021/bi500706x

Kawano, M., Kawakami, M., Otsuka, M., Yashima, H., Yaginuma, T., and Ueki, A. (1995). Marked decrease of plasma apolipoprotein AI and AII in Japanese patients with late-onset non-familial Alzheimer's disease. Clin. Chim. Acta 239, 209-211. doi: 10.1016/0009-8981(95)06115-T

Kim, J., Castellano, J. M., Jiang, H., Basak, J. M., Parsadanian, M., Pham, V., et al. (2009). Overexpression of low-density lipoprotein receptor in the brain markedly inhibits amyloid deposition and increases extracellular $\mathrm{A} \beta$ clearance. Neuron 64, 632-644. doi: 10.1016/j.neuron.2009.11.013

Kimura, T., Tomura, H., Mogi, C., Kuwabara, A., Damirin, A., Ishizuka, T., et al. (2006). Role of scavenger receptor class B type I and sphingosine 1phosphate receptors in high density lipoprotein-induced inhibition of adhesion molecule expression in endothelial cells. J. Biol. Chem. 281, 37457-37467. doi: 10.1074/jbc.M605823200

Ko, M., Zou, K., Minagawa, H., Yu, W., Gong, J. S., Yanagisawa, K., et al. (2005). Cholesterol-mediated neurite outgrowth is differently regulated between cortical and hippocampal neurons. J. Biol. Chem. 280, 42759-42765. doi: 10.1074/jbc.M509164200

Koutsis, G., Panas, M., Giogkaraki, E., Karadima, G., Sfagos, C., and Vassilopoulos, D. (2009). An APOA1 promoter polymorphism is associated with cognitive performance in patients with multiple sclerosis. Mult. Scler. 15, 174-179. doi: $10.1177 / 1352458508097217$

Leoni, V., Masterman, T., Patel, P., Meaney, S., Diczfalusy, U., and Bjorkhem, I. (2003). Side chain oxidized oxysterols in cerebrospinal fluid and the integrity of blood-brain and blood-cerebrospinal fluid barriers. J. Lipid Res. 44, 793-799. doi: 10.1194/jlr.M200434-JLR200

Levin, M. C., Douglas, J. N., Meyers, L., Lee, S., Shin, Y., and Gardner, L. A. (2014). Neurodegeneration in multiple sclerosis involves multiple pathogenic mechanisms. Degener. Neurol. Neuromuscul. Dis. 4, 1-15. doi: 10.2147/dnnd.s54391

Levin, M. C., Lee, S., Gardner, L. A., Shin, Y., Douglas, J. N., and Cooper, C. (2013). Autoantibodies to non-myelin antigens as contributors to the pathogenesis of multiple sclerosis. J. Clin. Cell. Immunol. 4, 1-21. doi: 10.4172/21559899.1000148

Lewis, T. L., Cao, D., Lu, H., Mans, R. A., Su, Y. R., Jungbauer, L., et al. (2010). Overexpression of human apolipoprotein A-I preserves cognitive function and attenuates neuroinflammation and cerebral amyloid angiopathy in a mouse model of Alzheimer disease. J. Biol. Chem. 285, 36958-36968. doi: 10.1074/jbc.M110.127829

Liu, G., Yang, K., Burns, S., Shrestha, S., and Chi, H. (2010). The S1P $\mathrm{P}_{1}$-mTOR axis directs the reciprocal differentiation of $\mathrm{T}_{H} 1$ and $\mathrm{T}_{\text {reg }}$ cells. Nat. Immunol. 11, 1047-1056. doi: 10.1038/ni.1939 
Liu, H. C., Hu, C. J., Chang, J. G., Sung, S. M., Lee, L. S., Yuan, R. Y., et al. (2006). Proteomic identification of lower apolipoprotein A-I in Alzheimer's disease. Dement. Geriatr. Cogn. Disord. 21, 155-161. doi: 10.1159/000090676

Locatelli, S., Lutjohann, D., Schmidt, H. H., Otto, C., Beisiegel, U., and von Bergmann, K. (2002). Reduction of plasma 24S-hydroxycholesterol (cerebrosterol) levels using high-dosage simvastatin in patients with hypercholesterolemia: evidence that simvastatin affects cholesterol metabolism in the human brain. Arch. Neurol. 59, 213-216. doi: 10.1001/archneur.59. 2.213

Lock, C. (2008). Are statins beneficial or harmful in multiple sclerosis? Neurology 71, e54-e55. doi: 10.1212/01.wnl.0000335940.94945.16

Louveau, A., Smirnov, I., Keyes, T. J., Eccles, J. D., Rouhani, S. J., Peske, J. D., et al. (2015). Structural and functional features of central nervous system lymphatic vessels. Nature 523, 337-341. doi: 10.1038/nature14432

Lund, E. G., Guileyardo, J. M., and Russell, D. W. (1999). cDNA cloning of cholesterol 24-hydroxylase, a mediator of cholesterol homeostasis in the brain. Proc. Natl. Acad. Sci. U.S.A. 96, 7238-7243. doi: 10.1073/pnas.96.13. 7238

Maier, O., De Jonge, J., Nomden, A., Hoekstra, D., and Baron, W. (2009). Lovastatin induces the formation of abnormal myelin-like membrane sheets in primary oligodendrocytes. Glia 57, 402-413. doi: 10.1002/glia.20769

Mailman, T., Hariharan, M., and Karten, B. (2011). Inhibition of neuronal cholesterol biosynthesis with lovastatin leads to impaired synaptic vesicle release even in the presence of lipoproteins or geranylgeraniol. J. Neurochem. 119, 1002-1015. doi: 10.1111/j.1471-4159.2011.07474.x

Mansoor, M., and Melendez, A. J. (2008). Recent trials for FTY720 (fingolimod): a new generation of immunomodulators structurally similar to sphingosine. Rev. Recent Clin. Trials 3, 62-69. doi: 10.2174/157488708783330486

Markovic-Plese, S., Jewells, V., and Speer, D. (2009). Combining beta interferon and atorvastatin may increase disease activity in multiple sclerosis. Neurology 72, 1965; author reply 1965-1966. doi: 10.1212/01.wnl.0000349667.27301.c8

Matthan, N. R., Giovanni, A., Schaefer, E. J., Brown, B. G., and Lichtenstein, A. H. (2003). Impact of simvastatin, niacin, and/or antioxidants on cholesterol metabolism in CAD patients with low HDL. J. Lipid Res. 44, 800-806. doi: 10.1194/jlr.M200439-JLR200

Mehling, M., Lindberg, R., Raulf, F., Kuhle, J., Hess, C., Kappos, L., et al. (2010). Th17 central memory T cells are reduced by FTY720 in patients with multiple sclerosis. Neurology 75, 403-410. doi: 10.1212/WNL.0b013e3181ebdd64

Meyers, L., Groover, C. J., Douglas, J., Lee, S., Brand, D., Levin, M. C., et al. (2014). A role for Apolipoprotein A-I in the pathogenesis of multiple sclerosis. J. Neuroimmunol. 277, 176-185. doi: 10.1016/j.jneuroim.2014.10.010

Mikael, L. G., Genest, J. Jr., and Rozen, R. (2006). Elevated homocysteine reduces apolipoprotein A-I expression in hyperhomocysteinemic mice and in males with coronary artery disease. Circ. Res. 98, 564-571. doi: 10.1161/01.RES.0000204825.66410.0b

Niino, M., Iwabuchi, K., Kikuchi, S., Ato, M., Morohashi, T., Ogata, A., et al. (2001). Amelioration of experimental autoimmune encephalomyelitis in C57BL/6 mice by an agonist of peroxisome proliferator-activated receptorgamma. J. Neuroimmunol. 116, 40-48. doi: 10.1016/S0165-5728(01)00285-5

Ong, W. Y., Kim, J. H., He, X., Chen, P., Farooqui, A. A., and Jenner, A. M. (2010). Changes in brain cholesterol metabolome after excitotoxicity. Mol. Neurobiol. 41, 299-313. doi: 10.1007/s12035-010-8099-3

Orth, M., and Bellosta, S. (2012). Cholesterol: its regulation and role in central nervous system disorders. Cholesterol 2012, 292598. doi: 10.1155/2012/292598

Pacheco, Y. M., Abia, R., Olivera, A., Spiegel, S., Ruiz-Gutierrez, V., and Muriana, F. J. (2003). Sphingosine 1-phosphate signal survival and mitogenesis are mediated by lipid-stereospecific binding of triacylglycerol-rich lipoproteins. Cell. Mol. Life Sci. 60, 2757-2766. doi: 10.1007/s00018-003-3323-1

Panin, L. E., Ryazantseva, N. V., Novitskii, V. V., and Tokareva, N. V. (2005). Apolipoprotein A-I possessing activity of defensin proteins modifies structure of plasma membranes. Bull. Exp. Biol. Med. 140, 406-409. doi: 10.1007/s10517005-0504-y

Pfrieger, F. W. (2003). Cholesterol homeostasis and function in neurons of the central nervous system. Cell. Mol. Life Sci. 60, 1158-1171. doi: 10.1007/s00018003-3018-7

Polak, P. E., Kalinin, S., Dello Russo, C., Gavrilyuk, V., Sharp, A., Peters, J. M., et al. (2005). Protective effects of a peroxisome proliferator-activated receptor- $\beta / \delta$ agonist in experimental autoimmune encephalomyelitis. J. Neuroimmunol. 168, 65-75. doi: 10.1016/j.jneuroim.2005.07.006
Prager, B., Spampinato, S. F., and Ransohoff, R. M. (2015). Sphingosine 1-phosphate signaling at the blood-brain barrier. Trends Mol. Med. 21, 354-363. doi: 10.1016/j.molmed.2015.03.006

Puglielli, L., Tanzi, R. E., and Kovacs, D. M. (2003). Alzheimer's disease: the cholesterol connection. Nat. Neurosci. 6, 345-351. doi: 10.1038/nn0403-345

Qi, X. F., Zheng, L., Lee, K. J., Kim, D. H., Kim, C. S., Cai, D. Q., et al. (2013). HMGCoA reductase inhibitors induce apoptosis of lymphoma cells by promoting ROS generation and regulating Akt, Erk and p38 signals via suppression of mevalonate pathway. Cell Death Dis. 4, e518. doi: 10.1038/cddis.2013.44

Robciuc, M. R., Metso, J., Sima, A., Ehnholm, C., and Jauhiainen, M. (2010). Human apoA-I increases macrophage foam cell derived PLTP activity without affecting the PLTP mass. Lipids Health Dis. 9, 59. doi: 10.1186/1476-511X-9-59

Roher, A. E., Maarouf, C. L., Sue, L. I., Hu, Y., Wilson, J., and Beach, T. G. (2009). Proteomics-derived cerebrospinal fluid markers of autopsy-confirmed Alzheimer's disease. Biomarkers 14, 493-501. doi: 10.3109/13547500903108423

Rudick, R. A., Pace, A., Rani, M. R., Hyde, R., Panzara, M., Appachi, S., et al. (2009). Effect of statins on clinical and molecular responses to intramuscular interferon beta-1a. Neurology 72, 1989-1993. doi: 10.1212/WNL.0b013e3181a92b96

Scanu, A. M., and Edelstein, C. (2008). HDL: bridging past and present with a look at the future. FASEB J. 22, 4044-4054. doi: 10.1096/fj.08-117150

Schmidt, S., Moric, E., Schmidt, M., Sastre, M., Feinstein, D. L., and Heneka, M. T. (2004). Anti-inflammatory and antiproliferative actions of PPAR-gamma agonists on $\mathrm{T}$ lymphocytes derived from MS patients. J. Leukoc. Biol. 75, 478-485. doi: 10.1189/jlb.0803402

Serban, C., Nicola, T., Mateescu, R., Noveanu, L., Susan, L., Pacurari, A., et al. (2010). Serum lipoprotein (a) levels in patients with arterial hypertension. Rev. Med. Chir. Soc. Med. Nat. Iasi 114, 798-802.

Shiga, Y., Miura, S., Mitsutake, R., Kawamura, A., Uehara, Y., and Saku, K. (2010). Significance of serum high-density lipoprotein cholesterol levels for diagnosis of coronary stenosis as determined by MDCT in patients with suspected coronary artery disease. J. Atheroscler. Thromb. 17, 870-878. doi: 10.5551/jat.3889

Simons, K., and Ikonen, E. (1997). Functional rafts in cell membranes. Nature 387, 569-572. doi: 10.1038/42408

Smith, S. A., Monteith, G. R., Robinson, J. A., Venkata, N. G., May, F. J., and RobertsThomson, S. J. (2004). Effect of the peroxisome proliferator-activated receptor beta activator GW0742 in rat cultured cerebellar granule neurons. J. Neurosci. Res. 77, 240-249. doi: 10.1002/jnr.20153

Song, F., Poljak, A., Crawford, J., Kochan, N. A., Wen, W., Cameron, B., et al. (2012). Plasma apolipoprotein levels are associated with cognitive status and decline in a community cohort of older individuals. PLoS ONE 7:e34078. doi: 10.1371/journal.pone.0034078

Song, G. J., Kim, S. M., Park, K. H., Kim, J., Choi, I., and Cho, K. H. (2015). SR-BI mediates high density lipoprotein (HDL)-induced anti-inflammatory effect in macrophages. Biochem. Biophys. Res. Commun. 457, 112-118. doi: $10.1016 /$ j.bbrc.2014.12.028

Sorci-Thomas, M. G., Owen, J. S., Fulp, B., Bhat, S., Zhu, X., Parks, J. S., et al. (2012). Nascent high density lipoproteins formed by ABCA1 resemble lipid rafts and are structurally organized by three apoA-I monomers. J. Lipid Res. 53, 1890-1909. doi: 10.1194/jlr.M026674

Sorensen, P. S., Lycke, J., Eralinna, J. P., Edland, A., Wu, X., Frederiksen, J. L., et al. (2011). Simvastatin as add-on therapy to interferon beta-1a for relapsing-remitting multiple sclerosis (SIMCOMBIN study): a placebocontrolled randomised phase 4 trial. Lancet Neurol. 10, 691-701. doi: 10.1016/S1474-4422(11)70144-2

Spampinato, S. F., Obermeier, B., Cotleur, A., Love, A., Takeshita, Y., Sano, Y., et al. (2015). Sphingosine 1 phosphate at the blood brain barrier: can the modulation of $\mathrm{s} 1 \mathrm{p}$ receptor 1 influence the response of endothelial cells and astrocytes to inflammatory stimuli? PLOS ONE 10:e0133392. doi: 10.1371/journal.pone.0133392

Spiegel, S., and Milstien, S. (2003). Sphingosine-1-phosphate: an enigmatic signalling lipid. Nat. Rev. Mol. Cell Biol. 4, 397-407. doi: 10.1038/nrm1103

Stukas, S., May, S., Wilkinson, A., Chan, J., Donkin, J., and Wellington, C. L. (2012). The LXR agonist GW3965 increases apoA-I protein levels in the central nervous system independent of ABCA1. Biochim. Biophys. Acta 1821, 536-546. doi: 10.1016/j.bbalip.2011.08.014

Takechi, R., Galloway, S., Pallebage-Gamarallage, M. M., Wellington, C. L., Johnsen, R. D., Dhaliwal, S. S., et al. (2010). Differential effects of dietary fatty acids on the cerebral distribution of plasma-derived apo B lipoproteins with amyloid- $\beta$. Br. J. Nutr. 103, 652-662. doi: 10.1017/S0007114509992194 
Tettey, P., Simpson, S. Jr., Taylor, B., Blizzard, L., Ponsonby, A. L., Dwyer, T., et al. (2014). An adverse lipid profile is associated with disability and progression in disability, in people with MS. Mult. Scler. 20, 1737-1744. doi: $10.1177 / 1352458514533162$

Toshniwal, P. K., and Zarling, E. J. (1992). Evidence for increased lipid peroxidation in multiple sclerosis. Neurochem. Res. 17, 205-207. doi: 10.1007/BF009 66801

Tsui-Pierchala, B. A., Encinas, M., Milbrandt, J., and Johnson, E. M. Jr. (2002). Lipid rafts in neuronal signaling and function. Trends Neurosci. 25, 412-417. doi: 10.1016/S0166-2236(02)02215-4

Vance, J. E. (2012). Dysregulation of cholesterol balance in the brain: contribution to neurodegenerative diseases. Dis. Model. Mech. 5, 746-755. doi: $10.1242 / \mathrm{dmm} .010124$

van de Kraats, C., Killestein, J., Popescu, V., Rijkers, E., Vrenken, H., Lutjohann, D., et al. (2014). Oxysterols and cholesterol precursors correlate to magnetic resonance imaging measures of neurodegeneration in multiple sclerosis. Mult. Scler. 20, 412-417. doi: 10.1177/1352458513499421

Van Doorn, R., Van Horssen, J., Verzijl, D., Witte, M., Ronken, E., Van Het Hof, B., et al. (2010). Sphingosine 1-phosphate receptor 1 and 3 are upregulated in multiple sclerosis lesions. Glia 58, 1465-1476. doi: 10.1002/glia.21021

Varga, T., Czimmerer, Z., and Nagy, L. (2011). PPARs are a unique set of fatty acid regulated transcription factors controlling both lipid metabolism and inflammation. Biochim. Biophys. Acta 1812, 1007-1022. doi: 10.1016/j.bbadis.2011.02.014

Vedhachalam, C., Duong, P. T., Nickel, M., Nguyen, D., Dhanasekaran, P., Saito, H., et al. (2007). Mechanism of ATP-binding cassette transporter A1-mediated cellular lipid efflux to apolipoprotein A-I and formation of high density lipoprotein particles. J. Biol. Chem. 282, 25123-25130. doi: 10.1074/jbc.M704590200

Vollbach, H., Heun, R., Morris, C. M., Edwardson, J. A., McKeith, I. G., Jessen, F., et al. (2005). APOA1 polymorphism influences risk for early-onset nonfamiliar AD. Ann. Neurol. 58, 436-441. doi: 10.1002/ana.20593
Vollmer, T., Key, L., Durkalski, V., Tyor, W., Corboy, J., Markovic-Plese, S., et al. (2004). Oral simvastatin treatment in relapsing-remitting multiple sclerosis. Lancet 363, 1607-1608. doi: 10.1016/S0140-6736(04)1 6205-3

Webb, N. R., Connell, P. M., Graf, G. A., Smart, E. J., de Villiers, W. J., de Beer, F. C., et al. (1998). SR-BII, an isoform of the scavenger receptor BI containing an alternate cytoplasmic tail, mediates lipid transfer between high density lipoprotein and cells. J. Biol. Chem. 273, 15241-15248. doi: $10.1074 /$ jbc. 273.24 .15241

Weinstock-Guttman, B., Zivadinov, R., Mahfooz, N., Carl, E., Drake, A., Schneider, J., et al. (2011). Serum lipid profiles are associated with disability and MRI outcomes in multiple sclerosis. J. Neuroinflammation 8, 127. doi: 10.1186/17422094-8-127

Wilhelm, A. J., Zabalawi, M., Grayson, J. M., Weant, A. E., Major, A. S., Owen, J., et al. (2009). Apolipoprotein A-I and its role in lymphocyte cholesterol homeostasis and autoimmunity. Arterioscler. Thromb. Vasc. Biol. 29, 843-849. doi: 10.1161/ATVBAHA.108.183442

Yang, Y., Gocke, A. R., Lovett-Racke, A., Drew, P. D., and Racke, M. K. (2008). PPAR alpha regulation of the immune response and autoimmune encephalomyelitis. PPAR Res. 2008, 546753. doi: 10.1155/2008/546753

Conflict of Interest Statement: Dr. Gardner became an employee of Novartis after initial submission of this manuscript. The authors declare that the research was conducted in the absence of any commercial or financial relationships that could be construed as a potential conflict of interest.

Copyright (C) 2015 Gardner and Levin. This is an open-access article distributed under the terms of the Creative Commons Attribution License (CC BY). The use, distribution or reproduction in other forums is permitted, provided the original author(s) or licensor are credited and that the original publication in this journal is cited, in accordance with accepted academic practice. No use, distribution or reproduction is permitted which does not comply with these terms. 